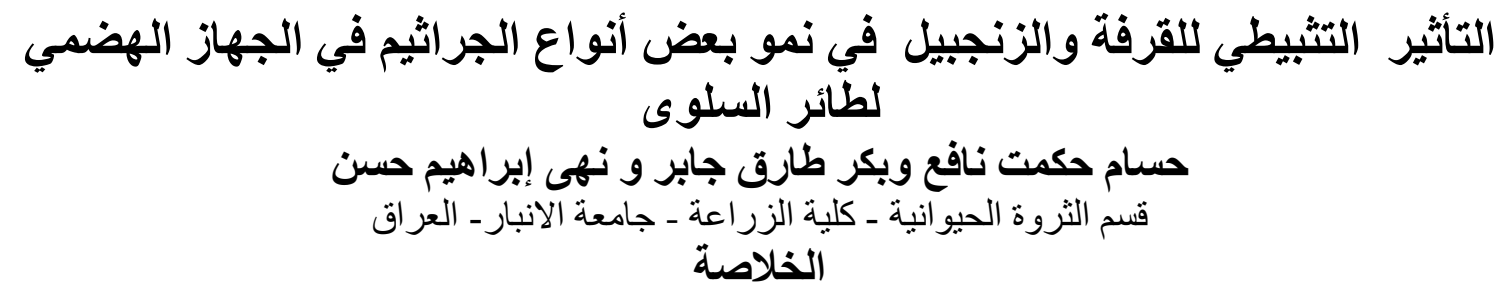

استهدفت التجربة دراسة التأثير ات الانفر ادية والتجميعية لإضافة مجروش القرفة و والزنجبيل إلى العليقة بمستويات

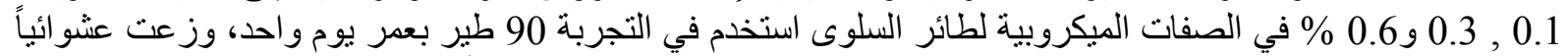

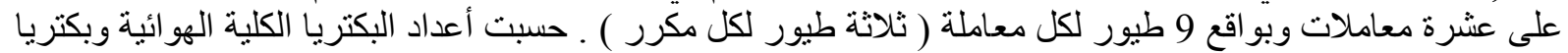

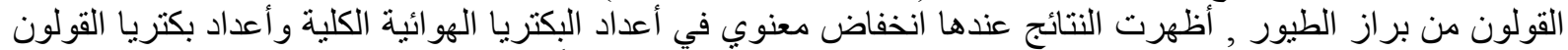

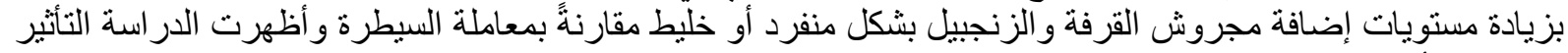
التثبيطي لأعداد بكتريا القولون والبكتريا الهوائية عند إضافة مستويات مختلفة من مجروش الزئنة الزبيلة الزبيل مقارنة بمعاملات القرفة و الخليط في العليقة الكلمات المفتاحية: القرفة، الزنجبيل ، الجهاز الهضمي ، السلوي .

\title{
The Inhibitory Effect of Cinnamon (Cinnamomum zeylhnicum) and Ginger (Zingiber officinal) in the Growth of Some Bacterial Species in the Gastrointestinal Tract of the Quail
} Husam H. Nafia,BaKer T. Jaber and Nuha I. Hasan

Department of Animal Resource, Agriculture College, University of Anbar, Iraq Accepted 25 /12/2011

\section{Summary}

This experiment conducted for studying the effects of crushed cinnamon and ginger to the diet at levels $0.1,0.3,0.6 \%$ in the bacterial growth of gastrointestinal tract of the quail. Ninety birds one day age divided randomly into ten transactions as 9 birds per treatment (three birds per duplicate). The numbers of bacteria, total aerobic bacteria in the colon of feces of birds were calculated, the results showed a significant reduction in the number of aerobic bacteria and the numbers of bacteria in the colon. Proportionally increase in the levels of crushed cinnamon, ginger, individually or in combination in comparison the control group showed influence inhibitory to the numbers of bacteria in the colon and aerobic bacteria when you add different levels of transactions compared to crushed ginger and cinnamon mixture into the bush.

Keywords: Cinnamona, Ginger, inhibitory effect, GIT, Quail.

\section{المقدمة}

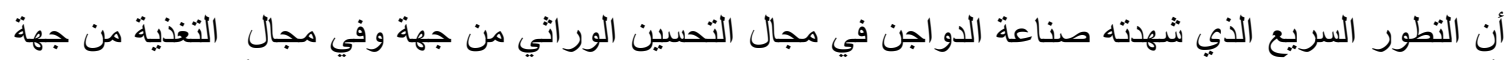

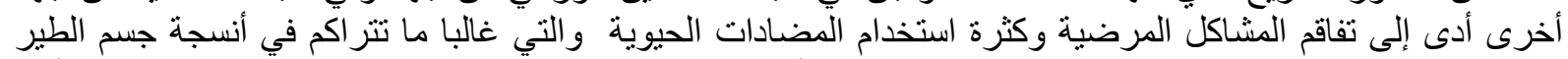

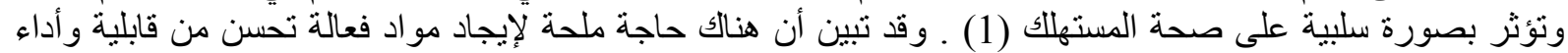

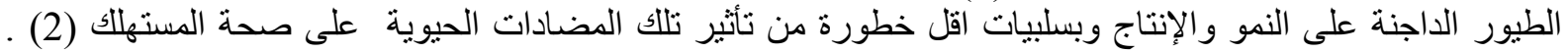

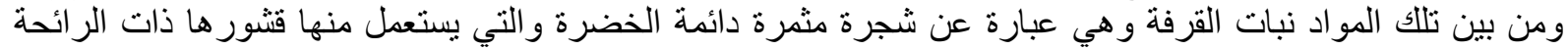

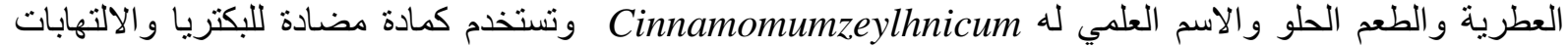
الفطرية و الفايروسية وتعمل على تنبيه القلب وتنشيطه وتنشيط الدورة الدموية إضافة إلى احتو ائها على مادة السينمالدهايد

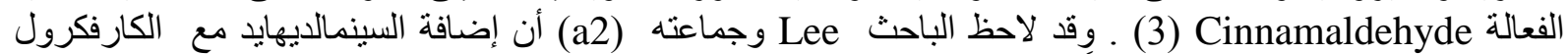

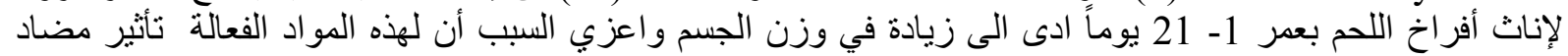

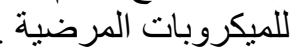

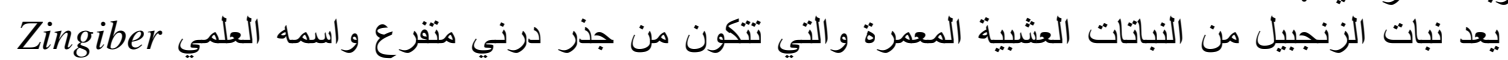

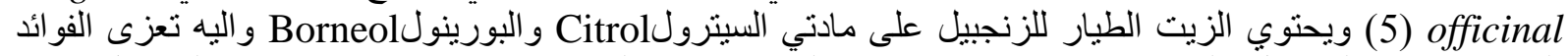

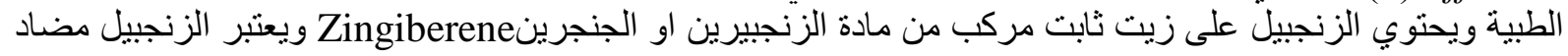


للبكتريا ويفيد في علاج عسر الهضم ويوسع الاوعية الدموية ويخفض معدل الكولستيرول ويقاوم الالتهابات (6) ـ ـوقد

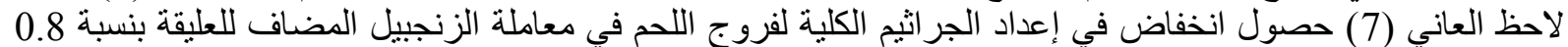

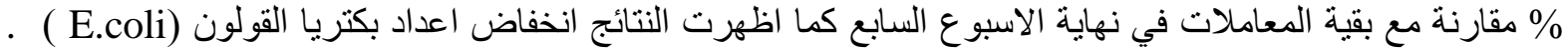

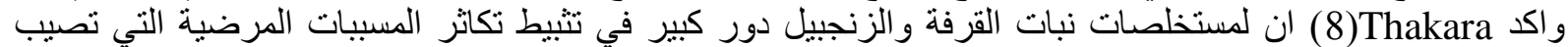

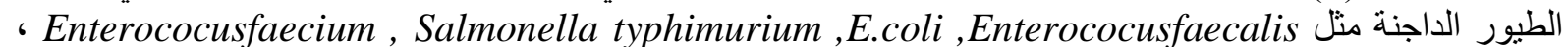

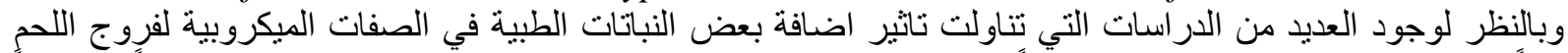

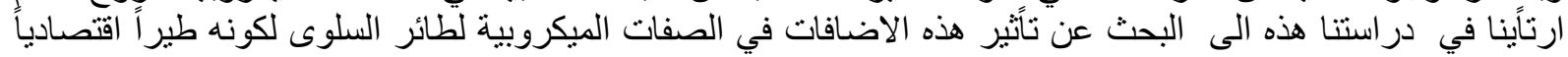

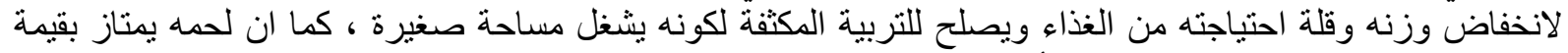

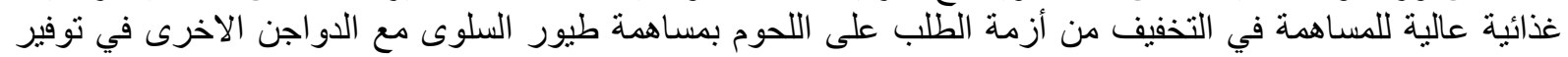
اللحوم (10,9) . ولقلة الدراسات في مجال ناثير هذة الاضافات في الصفات الميكروبية لطائر السلوى فقد جائت هذة

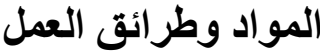

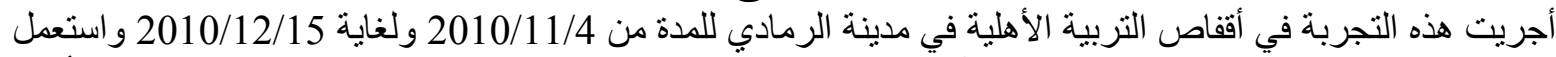

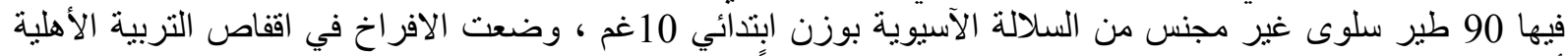

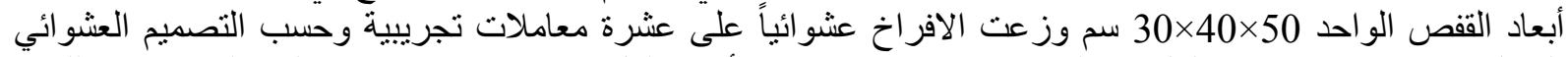

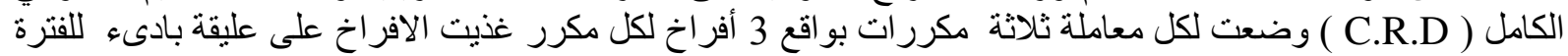

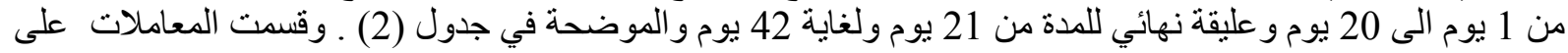

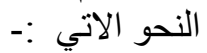

المعاملة الاولى ( T1 ) معاملة السيطرة استعملت عليقة طيور السلوى خالية من ايه اضافة .

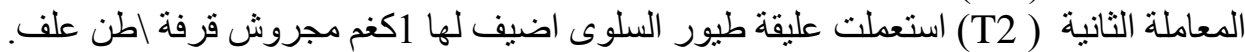

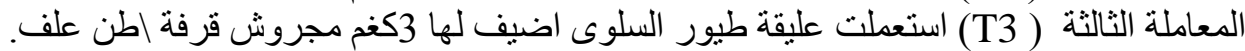

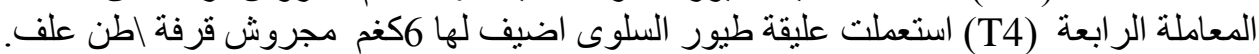

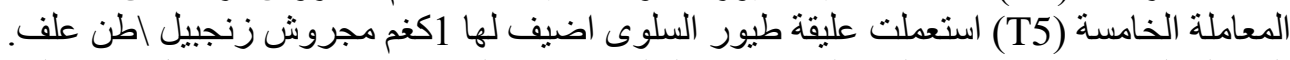

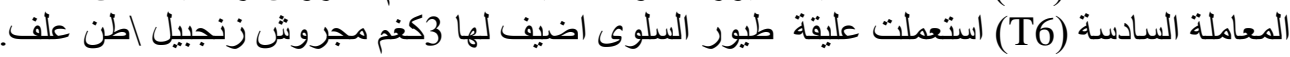

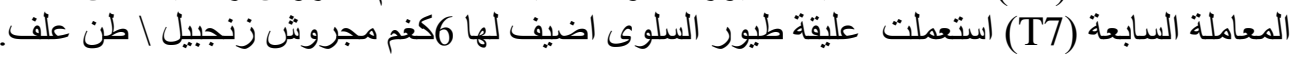

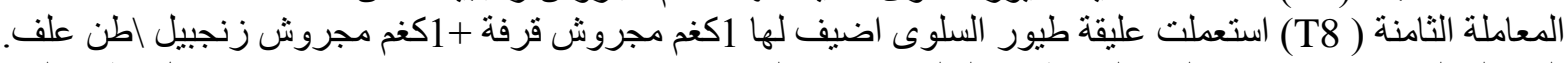

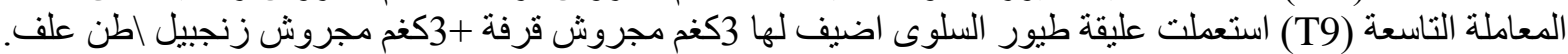

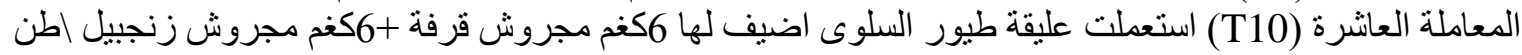

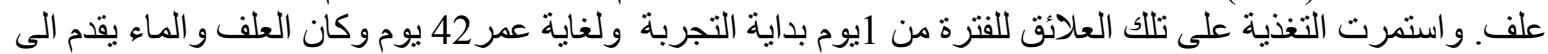

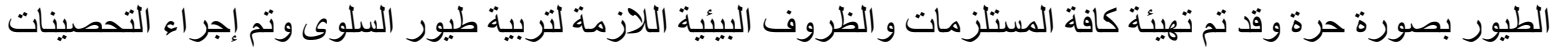

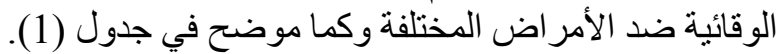

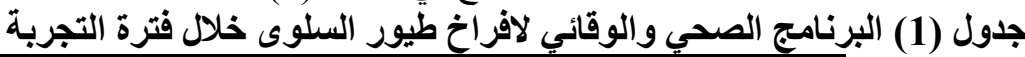

\begin{tabular}{|c|c|}
\hline 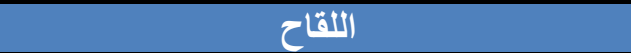 & العمر / يوم \\
\hline لقاح نيوكاسل ND نوع لاسوتا عن طريق الرش & 3 \\
\hline لَّاح نيوكاسل ND ثَاني عن طريق الرش & 7 \\
\hline لقاح كمبورو IBD عن طرق ماء الشرب & 9 \\
\hline لقاح نيوكاسل NDD ثالث عن طريق الرش & 15 \\
\hline لقاح كمبورو IBD ثاني عن طرق ماء الشرب & 19 \\
\hline لَقاح نيوكاسل NDالت عن طريق الرش & 25 \\
\hline
\end{tabular}

وتم إعطاء فيتامين AD3E بعد كل تلقيح 5 مل /20 لتر ماء لمدة 2 يوم نيوكام

تم الحصول على القرفة السيلانية و الزنجبيل من السوق المحلية لمدينة الرمادي ـ وتم اجراء العاء هذة الدراسة في مختبر

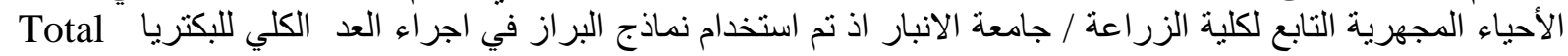

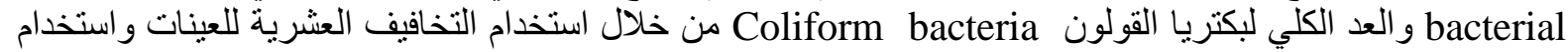

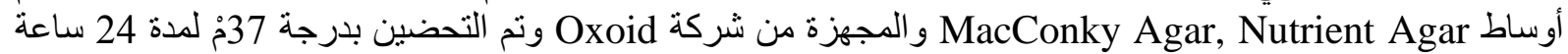

وحسبت اعداد البكتريا الكلية الهو ائية وبكتريا القولون (11) . 


\begin{tabular}{|c|c|c|}
\hline \multicolumn{3}{|c|}{ جدول (2) مكونات عليقة البادئ والنهائي المستخدمة في التجربة } \\
\hline \% اليقة الأنهائي \% & 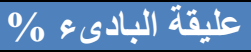 & المواد العالفية \\
\hline 38 & 34.5 & ذزة صفز او \\
\hline 30 & 24 & هنطة \\
\hline 20 & 30 & كسبة فول الصويا (44\%) \\
\hline 10 & 10 & مركز بروتيني حيواني1 \\
\hline 0.75 & 0.75 & فوسفات الكالسيوم الثشائية \\
\hline 0.25 & 0.25 & ملح طعام \\
\hline 1 & 0.50 & زيت نباتي \\
\hline 100 & 100 & المجموع \\
\hline \multicolumn{3}{|c|}{ التركيب الكيميائي المسوب (2) } \\
\hline 19.02 & 22.625 & البروتين الخام \% \\
\hline 2974 & 2873.5 & طاقة ممثلة Kg/ Kcal \\
\hline 0.99 & 1.35 & لايسين \% \\
\hline 0.61 & 0.58 & ميشيونين \% \\
\hline 0.58 & 0.70 & مشيونين +سستين \% \\
\hline 3.7 & 1.2 & كالسيوم \% \\
\hline 0.34 & 0.53 & 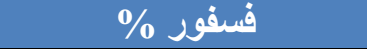 \\
\hline
\end{tabular}

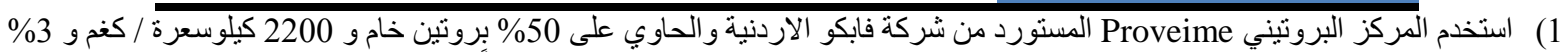

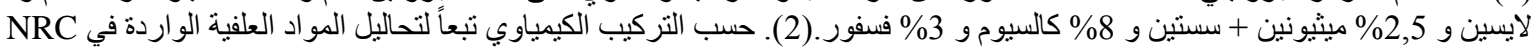

\section{النتائج والمناقشة المزئة}

يبين جدول (3) التاثير ات الانفر ادية لاضافة مجروش القرفة الى العليقة في الاعداد البكتيرية الكلية وكذلك الكادية اعداد بكتريا

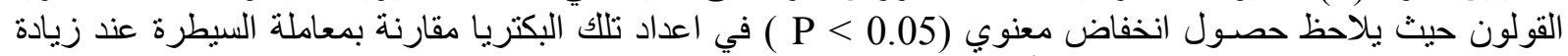

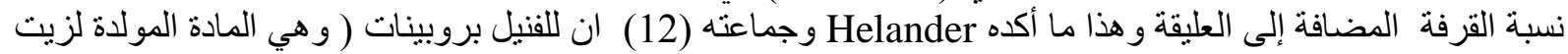

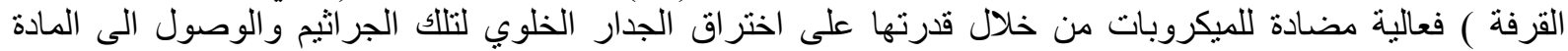

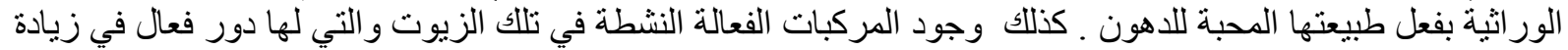

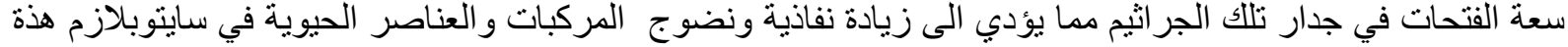

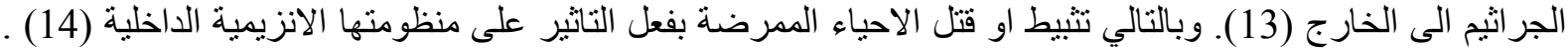

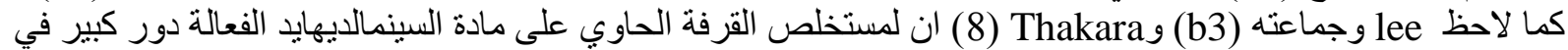
تثتيط الاعداد الكلية للبكتريا الهو ائية وبكتريا القولون .

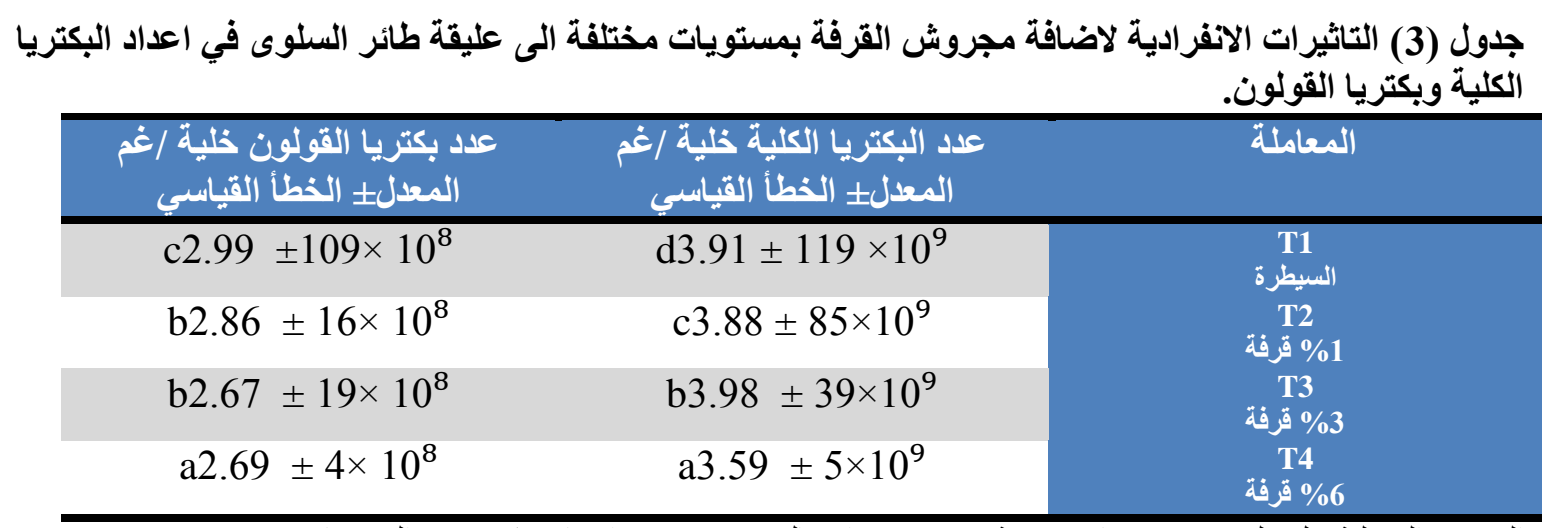

الحروف المختلفة تدل على وجود فروقات معنوية عند مستوى احتمال 0.05 وحسب اختبار دنكن متعدد المستويات.

يبين جدول (4 ) الناثير ات الانفر ادية لاضافة مجروش الزنجبيل الى العليقة غلى الاعداد البكتيرية الكلية وكذلك اعداد

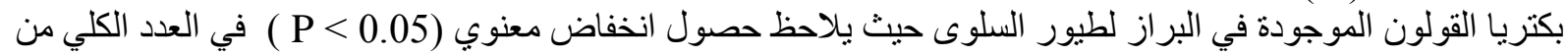

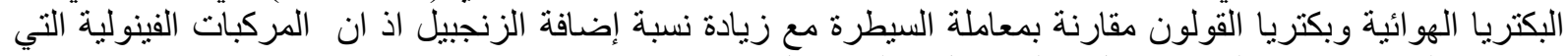

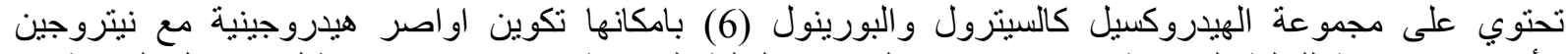
الأحماض الامينية للخلية البكتيرية او مع جزيئات الماء في الخلية البكتيرية مما يتسبب في تعطيل الاعمال الحيوية في 
الخلية البكتيرية ـ كما تمتلاك هذة المركبات الفينولية القدرة على اذابة الطبقة الدهنية لجدار الخلية البكتيرية مما يسبب في

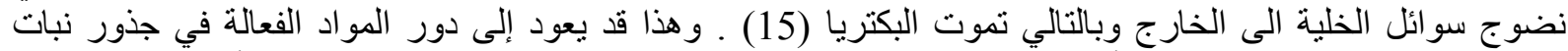

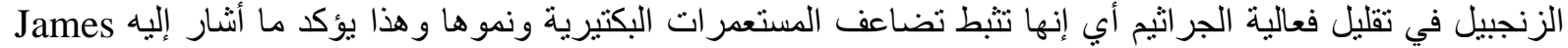

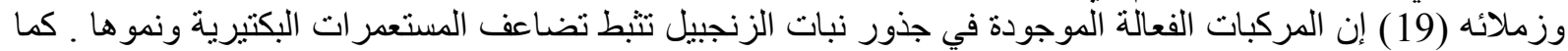

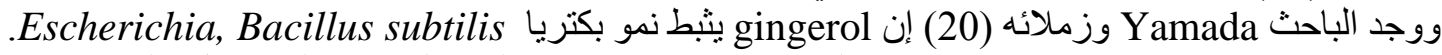

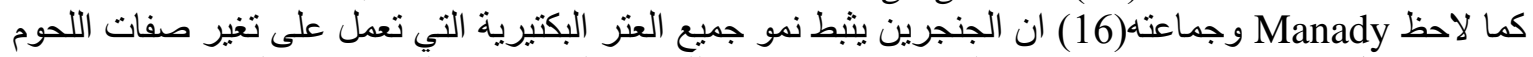

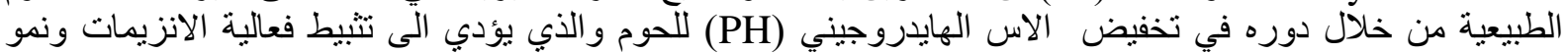

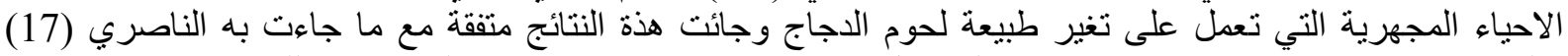

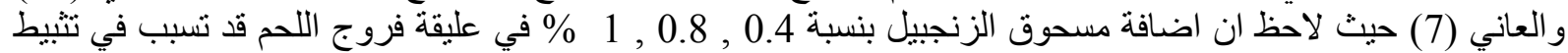
نمو جميع العتر البكتيرية الهو ائية وبكتريا القولون الفئ

جدول (4) التاثيرات الانفرادية لاضافة مجروش الزنجبيل بمستويات مختلفة الى عليقة طائر السلوى في اعداد البكتريا

\begin{tabular}{|c|c|c|}
\hline 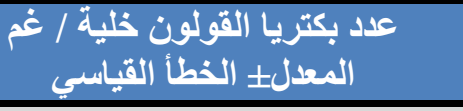 & 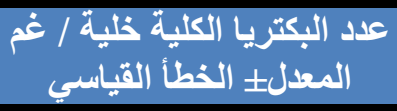 & المعاملة: \\
\hline $\mathrm{d} 3.74 \pm 109 \times 10^{9}$ & d $4.97 \pm 97 \times 10$ & السيطرة \\
\hline c $3.10 \pm 22 \times 10^{9}$ & c $3.99 \pm 40 \times 10^{9}$ & $\begin{array}{l}\text { T5 } \\
\text { زنجيل 0.1 } 0.1\end{array}$ \\
\hline b2.39 $\pm 14 \times 10^{9}$ & b3.87 $\pm 19 \times 10^{9}$ & $\begin{array}{l}\text { T6 } \\
0.3\end{array}$ \\
\hline $\mathrm{a} 2.43 \pm 2 \times 10^{9}$ & a3.98 $\pm 5 \times 10^{9}$ & T7 \\
\hline
\end{tabular}

الحروف المختلفة تدل على وجود فروقات معنوية عند مستوى احتمال 0.05 وحسب اختبار دنكن متعدد المستويات.

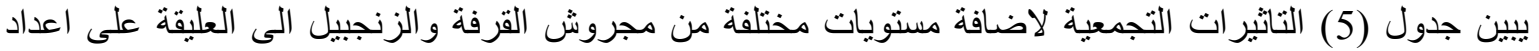

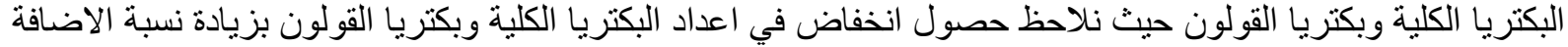

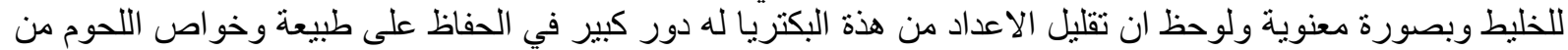

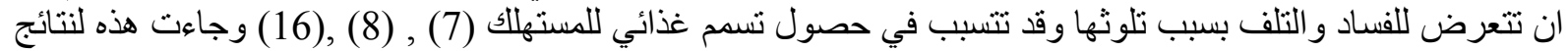

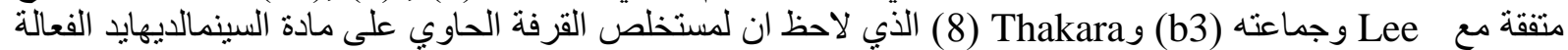

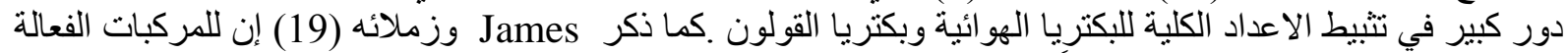

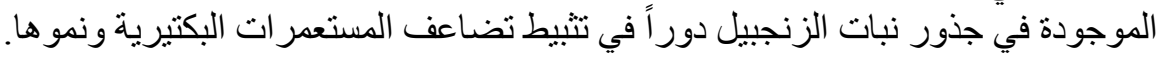

\begin{tabular}{|c|c|c|}
\hline 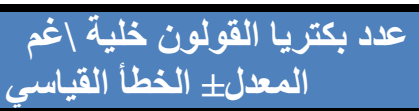 & 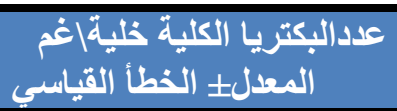 & المعاملة: \\
\hline $\mathrm{d} 3.10 \pm 106 \times 10^{9}$ & $\mathrm{c} 4.43 \pm 101 \times 10^{10}$ & السيطرة \\
\hline c $3.50 \pm 40 \times 10^{9}$ & b4. $22 \pm 130 \times 10^{9}$ & 0.1\% 0رفة 0.1\% 0زنجبيل \\
\hline$b 2.63 \pm 10 \times 10^{8}$ & ab2.48 $\pm 96 \times 10^{9}$ & 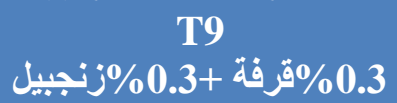 \\
\hline a2. $93 \pm 2 \times 10^{8}$ & a3.87 $\pm 90 \times 10^{9}$ & T10 \\
\hline
\end{tabular}

الحروف المختلفة تدل على وجود فروقات معنوية عند مستوى احتمال 0.05 وحسب اختبار دنكن متعدد المستويات.

\section{المصادر}

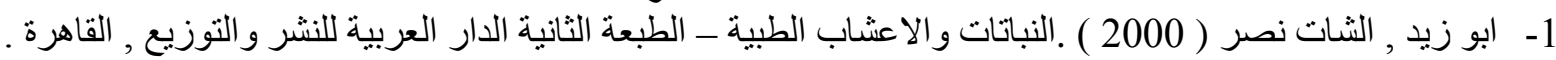

2- Lee, KW.; Everts, H. and Beynen, AC. ( 2004). Essential oils in Broiler Nutrition. MSc. Thesis, Faculty of Veterinary Medicine, Utrecht University, Netherlands. 
3- Lee, KW. ; Everts, H.; Kappert, HJ. and Beynen, AC. (2004). Growth performance of Broiler chickens fed acarboxymethyl cellulose containing Diet with supplemental car vacrol and $\backslash$ or cinnamaldehyde. Inter. J. Poultry Sci., 3 (9): 619-622.

4- Furia, TE. and Bellanca, N. (1975). Fenarolis handbook of flavor ingredients. In Adapted from the Italian language works. $2^{\text {nd }}$ Ed. crc press, Ohio .

5- عرموش , هاني .(2007). الاعثاب , الاستخدامات الطبية والعلاجية و التجميلية والتصنيعية , الطبعة الرابعة . العربية للنشر والتوزيع , القاهرة .

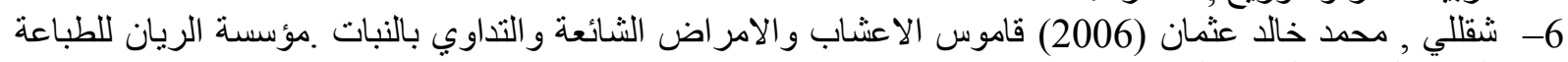

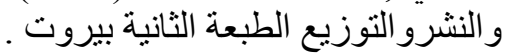

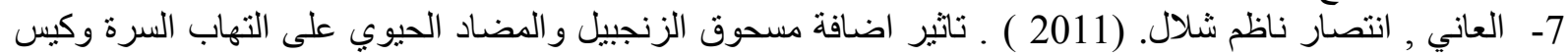

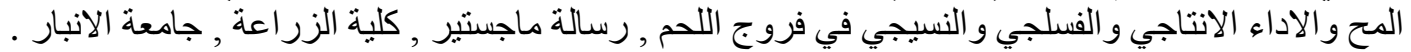

8- Thakara, M. (2004). Pharmacological screening of some Medicinal plants As Antimicrobial and Feed Additives. Master Thesis, Virginia Polytechnic institute and state University, Blacksburg, Virginia, USA.

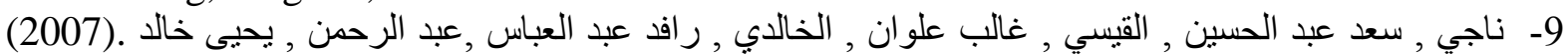

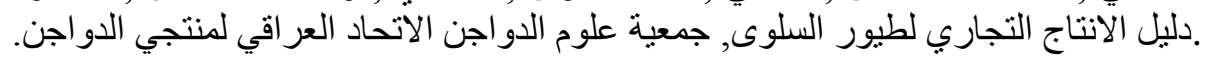

10- Sharma, D.; Appa, KB. and Toty, SM. (2000). Measurement of Within And Between Population Genetic Variability In quail. Br. Poult. Sci., 52:456-473.

11- Cruickshank, R.; Duguid, JP.; Marmion, BP. and Swain, RH. (1975). Medical Microbiology. In Practice of Medical Microbiology. $12^{\text {th }}$ Ed. Churchill, Livingstone, Edinburgh.

12- Helander, IM.; Alakomi, HL. ; latva - kala, K.; Mattila- sandholm , T.; Pol, I., Smid , EJ.; Corris, L.G. and Von wright, A. (1998). Characterization of action of selected essential oil components on Gramnegative bacteria. J. Agr. Food chem., 46:3590 -3595.

13- Juven, BJ.; Kanner, J.; Schved, F. and Weisslowicz, H. (1994). Factors that interact with the antibacterial action of thyme essential oil and its active constituents. J. Appl. Bacteriol., 76: $626-631$.

14- Farag, RS.; Daw ZY. ; Hewed, FM. and EL-Baroty, GS.(1989). Antimicrobial activity of some Egyptian Spice essential oils .j Food Protec., 52 : 665-667.

15- Sartoratto, A.; Machado, AL.; Delarmelina, C.; Figueira, GM.; Duarte, MC. and Rehder, VL. ( 2004). Composition and antimicrobial activity of essential oils from aromatic plants used in Brazil. Brazilian J. . Micro., 35:275-280

16- Mahady, GB.; Pendlard Yun, GS.; Lu, ZZ. and Stoia, A. (2003). Ginger (Zingiber officinal roscoe) and Gigerol inhibit the Growth of Cag At strains of Helicobacter Pylor: Anticancer.

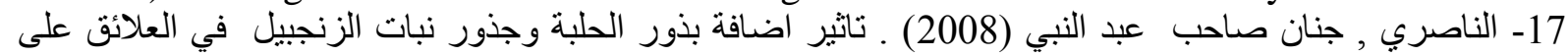

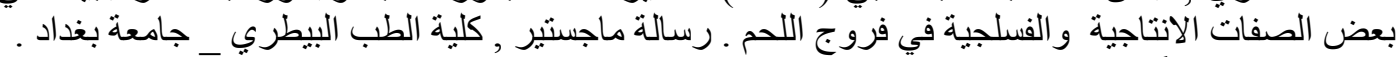

18- National Research Council (NRC) (1994) Nutrient Requirement of poultry. $9^{\text {th }}$ Ed. National Academy press, Washington.

19-James, ME.; Nannapaneni, R. and Johuson, MG.(1999). Identification and characterization of two bacteriocin-producing bacteria isolated from garlic and ginger root. J. food Port., 62: $889-901$.

20-Yamada, Y.; Kikuzaki, H. and Nakatani, N. (1992). Identification of antimicrobial gingerols from ginger (Zingiber officinale). J. Antibact. antifungal agents, 20:309 -311. 